\title{
Crushing and flexural strength of slab-column joints
}

\author{
Roberto Guidotti, Miguel Fernández Ruiz*, Aurelio Muttoni \\ Ecole Polytechnique Fédérale de Lausanne, Station 18, CH-1015 Lausanne, Switzerland
}

\section{A R T I C L E I N F O}

\section{Article history:}

Received 10 June 2010

Received in revised form

3 November 2010

Accepted 1 December 2010

Available online 30 December 2010

\section{Keywords:}

Flat slabs

Concrete crushing

Slab-column joints

Theory of plasticity

\begin{abstract}
A B S T R A C T
In multi-storey buildings, columns are usually not continuous through the slabs to enhance ease of construction. Consequently, in slab-column joints, slabs have to carry column loads in addition to the shear and bending moments due to loads applied to the slab. In most cases, when high strength concrete is used for the columns and normal strength concrete for the slabs, compression stresses at the support areas of the inner columns exceed the uniaxial compressive strength of the concrete of the slab. Due to this reason, most current details for such regions reinforce the concrete of the slab between columns to ensure load transfer. Typically, this is achieved by linking top and bottom columns with reinforcement. Sometimes, it is also needed to incorporate special load transfer devices. This latter solution is however relatively complicated and expensive.

In this paper, the crushing and flexural strength of slab-column joints is investigated accounting for an increase of the compressive strength of the failure region (concrete between columns) due to confinement stresses provided by the flexural reinforcement of the slab. The results of an experimental programme on 6 full-scale slabs (250 mm thick) are presented showing that flexural reinforcement of a slab significantly increases the crushing strength of slab-column joints. This allows ensuring load transfer without incorporating special devices or even without linking top and bottom column reinforcement for a wide range of cases leading potentially to more economic designs. An analytical approach, grounded on the theory of plasticity, is also presented allowing one to determine a failure criterion for such regions. This approach, which can also be used for design purposes, leads to an excellent correlation with test results. (c) 2010 Elsevier Ltd. All rights reserved.
\end{abstract}

\section{Introduction}

Reinforced concrete flat slabs supported by columns are currently one of the most widespread structural solutions for multistorey buildings, with columns cast in situ (Fig. 1(a)) or precast with steel plates at their ends (Fig. 1(b)). The slabs are typically cast in normal strength concrete (specified concrete compressive strength around $30 \mathrm{MPa}$ ) whereas the columns are usually cast using high strength concrete (with a specified compressive strength between 60 and $120 \mathrm{MPa}$ ). Due to the lower compressive strength of the slab, crushing of the slab at the slab-column joint may potentially be governing for design.

The crushing strength of the joint $\left(N_{R}\right)$ can be calculated as the sum of the compression strength of the concrete of the slab $\left(N_{c, R}\right)$ plus the strength of the reinforcing bars linking the upper and lower columns $\left(N_{s, R}\right.$ see Fig. 1(a)). In the case where the eccentricity of the column load can be neglected it results in:

$N_{R}=N_{c, R}+N_{s, R}=f_{c c}\left(A_{c}-A_{s}\right)+f_{y} A_{s}$

\footnotetext{
* Corresponding author.

E-mail addresses: roberto.guidotti@epfl.ch (R. Guidotti), miguel.fernandezruiz@epfl.ch (M. Fernández Ruiz), aurelio.muttoni@epfl.ch (A. Muttoni)
}

where $f_{c c}$ refers to the confined crushing strength of concrete, $f_{y}$ to the yield strength of the reinforcement, $A_{c}$ to the column support area and $A_{s}$ to the reinforcement area. In current design practice and if no special confinement reinforcement is available, $f_{c c}$ is typically replaced by $f_{c}$ (concrete uniaxial compressive strength), neglecting the potential confinement of the failure region provided by the flexural reinforcement of the slab. In order to ensure sufficient strength, some structural solutions have been developed in the past, following two basic principles:

1. Increasing the concrete strength of the slab $f_{c c}$. This can be achieved by casting the slab near the columns in high strength concrete (Fig. 1(e)) or by placing confinement reinforcement around the columns. Although the flexural reinforcement (Fig. 1(b)) can provide a certain level of confinement, circular stirrups are typically used as confinement reinforcement in the slab (Fig. 1(f)).

2. Incorporating special (typically steel) devices, allowing it to carry the compression of the columns through the slab (Fig. 1(c)), in order to increase the reinforcement strength $N_{s, R}$. These devices can is some cases be combined with corrugated surfaces for the introduction of the shear forces (Fig. 1(d)).

From the aforementioned solutions to increase concrete compressive strength, the most economic one is that of providing confinement only by means of the flexural reinforcement (Fig. 1(a,b)). 


\section{Notations}

The following symbols are used in the paper:

A surface $\left(A_{c}\right.$ column surface; $A_{s}$ reinforcement connecting upper and lower columns surface)

E modulus of elasticity ( $E_{c}$ concrete; $E_{c c}$ confined concrete)

$N \quad$ column load ( $N_{c}$ column load carried by the concrete of the slab; $N_{c, 3}$ joint without slab load strength; $N_{c, R}$ at failure; $N_{c, R, \text { calc }}$ calculated at failure; $N_{c, R, \text { test }}$ measured at failure; $N_{c, T}$ at point 2 on the interaction diagram; $N_{c, \max }$ maximal column load on the interaction diagram; $N_{R}$ column load at failure; $N_{s, R}$ column load carried by reinforcement connecting upper and lower columns at failure)

$Q \quad$ slab load $\left(Q_{T}\right.$ at point 2 on the interaction diagram; $Q_{R}$ at failure; $Q_{R \text {,test }}$ measured at failure; $Q_{\text {flex }}$ flexural strength for joint without column load; $Q\left(N_{c, \max }\right)$ at maximal column load on the interaction diagram)

$R \quad$ plastic cylinder radius

a confinement stress coefficient

$a_{\varepsilon}, b_{\varepsilon}, c_{\varepsilon}$ axial-radial strain law parameters

$b \quad$ slab dimension $\left(b_{n}\right.$ width of the slab used for confinement of inner prism; $b_{q}$ position of applied loads; $b_{s}$ slab width)

c square column dimension

$d$ distance between concrete bottom surface and top reinforcement (average of the 3rd and the 4th layer)

$d^{\prime} \quad$ distance between concrete top surface and bottom reinforcement (average of the 1st and the 2nd layer) $f \quad$ strength $\left(f_{c}\right.$ compressive strength of concrete measured on cylinders; $f_{c c}$ compressive strength of confined concrete cylinder; $f_{c, e}$ compressive effective concrete strength; $f_{c t}$ tensile strength of concrete; $f_{y}$ yield strength of reinforcement; $f_{y}^{\prime}$ yield strength of bottom reinforcement)

$h$ thickness of the slab, the cylinder or the confinement ring

$k \quad$ coefficient accounting for compressive strength increase due to uniform confinement stresses $\left(k_{m}\right.$ used for non-uniform confinement)

$l \quad$ span length of a flat slab ( $l_{0}$ cantilever overhang)

$m$ bending moment per unit length $\left(m_{p l}\right.$ plastic bending moment for the yield line over the support region; $m_{p l, 2}^{+}, m_{p l, 2}^{-}$positive and negative plastic bending moment in the yield line at mid span)

normal force per unit length $\left(n_{c}, n_{s}, n_{s}^{\prime}\right.$ concrete, top reinforcement and bottom reinforcement forces; $n_{\text {lat }}$ resultant confinement force; $n_{p l}$ normal force of the outer confinement ring at full yielding)

$r \quad$ radial dimension $\left(r_{c}\right.$ column radius)

$t \quad$ plasticized height

$w \quad$ vertical displacement $\left(w_{0}\right.$ bottom column penetration in plastic mechanism; $w_{c}$ sum of the top and bottom column penetration; $w_{c R \text {, test }}$ sum of the top and bottom column penetration measured at failure)

$x \quad$ height of compression chord

$z \quad$ vertical coordinate $\left(z_{c}\right.$ distance between soffit of the slab and the resultant of confinement stresses in the case where no loads are applied on the slab; $z_{\text {lat }}$ distance between soffit of the slab and confinement resultant force)

\begin{tabular}{|c|c|}
\hline$\Delta Q^{+,-}$ & $\begin{array}{l}\text { slab load contribution of the positive and negative } \\
\text { mid span yield line }\end{array}$ \\
\hline$\alpha$ & $\begin{array}{l}\text { concrete brittleness coefficient ( } \alpha_{c} \text { for unconfined } \\
\text { concrete) }\end{array}$ \\
\hline$\alpha_{f} ; \beta_{f}$ & confined concrete law factors \\
\hline$\gamma$ & confinement ratio \\
\hline$\delta$ & ratio between confined and unconfined response \\
\hline$\varepsilon$ & $\begin{array}{l}\text { normal strain ( } \dot{\varepsilon} \text { plastic strain; } \varepsilon_{1} \text { lateral strain in } \\
\text { a concrete cylinder; } \varepsilon_{3} \text { axial strain in a concrete } \\
\text { cylinder; } \varepsilon_{1, e}, \varepsilon_{3, e} \text { lateral and axial strain at } 0.8 f_{c c} \text { in } \\
\text { a concrete cylinder; } \varepsilon_{1, p}, \varepsilon_{3, p} \text { lateral and axial strain } \\
\text { at peak load in a concrete cylinder) }\end{array}$ \\
\hline$\vartheta$ & angular coordinate \\
\hline$v$ & Poisson's ratio ( $v_{c}$ concrete elastic Poisson's ratio) \\
\hline$\rho \mathrm{s} \rho^{\prime}$ & top and bottom flexural reinforcement ratio \\
\hline$\sigma$ & $\begin{array}{l}\text { normal stress }\left(\sigma_{1}, \sigma_{2} \text { principal stresses; } \sigma_{3} \text { axial }\right. \\
\text { stress in a concrete cylinder (principal stress); } \\
\sigma_{c} \text { in concrete; } \sigma_{\text {lat }, 1}, \sigma_{\text {lat }, 2} \text { minimal and maximal } \\
\text { confinement stress; } \sigma_{\text {lat }} \text { confinement stress; } \sigma_{\text {lat }} \text {, } \\
m \text { average confinement stress; } \sigma_{p l} \text { plastic stresses } \\
\text { under column plate; } \sigma_{s} \text { stress in top reinforcement; } \\
\sigma_{s}^{\prime} \text { stress in bottom reinforcement) }\end{array}$ \\
\hline$\tau$ & tangential stresses \\
\hline$\varphi$ & friction angle of Mohr-Coulomb material \\
\hline$\psi$ & slab rotation \\
\hline$\omega$ & $\begin{array}{l}\text { mechanical reinforcement ratio }\left(\omega_{t} \text { in the tangential }\right. \\
\text { direction; } \tilde{\omega}_{t} \text { effective mechanical reinforcement } \\
\text { ratio in the tangential direction) }\end{array}$ \\
\hline
\end{tabular}

It also presents some additional advantages such as increasing the punching shear strength of the slab or enhancing its deformation capacity [1]. Many researchers [2-6] have investigated the behaviour of this type of joint. In most cases, the aim has been to investigate its strength when the joint is subjected to loads coming only from cast-in-situ columns. First works were developed by Bianchini et al. [2] in 1960 leading to an empirical design approach accounting for the concrete strength of the slab and of the columns. In 1991, the thicknesses of the slab and of the column size were also accounted by Ospina and Alexander [4]. Shah et al. [6] also developed a formulation allowing one to consider the influence of the flexural reinforcement ratio and of loads applied to the slab. These researches focused mainly on the reduction of the strength of columns due to flexural cracking of the slab.

This paper presents the results of a test programme on 6 fullscale slab specimens. The tests were performed with the aim of investigating the influence and the interaction between column forces and slab loads on the crushing strength of slab-column joints assuming that the column strength is not governing. The specimens were subjected to loads applied on the column region by means of steel plates $\left(N_{c}\right.$, simulating precast column loading, Fig. 1(b)). Two specimens also had loads applied to the slab ( $Q$, simulating flat slab loads) in order to investigate the influence of the slab bending on the joint strength. A physical model, suitable for predicting the behaviour of inner slab-column joints for columns with continuous reinforcement or with support plates (typical cases of cast-in-situ or precast columns, Fig. 1(a, b)) is also presented. The model is grounded on the theory of plasticity and allows calculating the strength of slab-column joints accounting for the development of confinement stresses in the failure region (between column loads).

It should be noted that slab-column joints may also fail by punching of the slab around the support region (for low or moderate values of $N_{c}$ ). A suitable approach for this problem and compatible with the concepts presented within this paper has been published by the authors elsewhere [7]. 

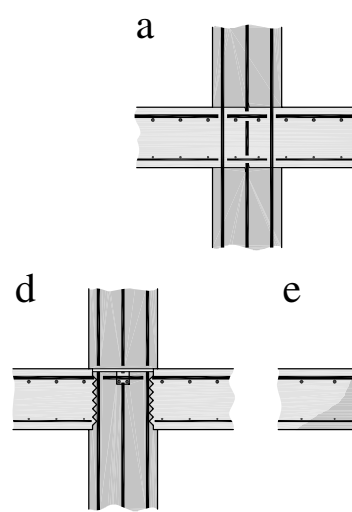

e
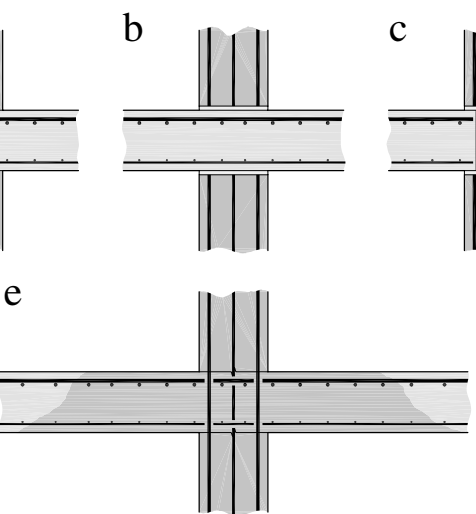
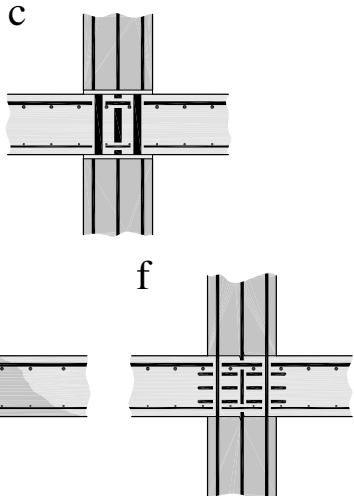

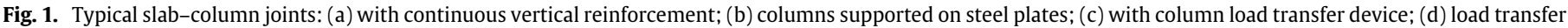
device with corrugated surface; (e) slab with high strength concrete near columns; and (f) with confinement rings.

a

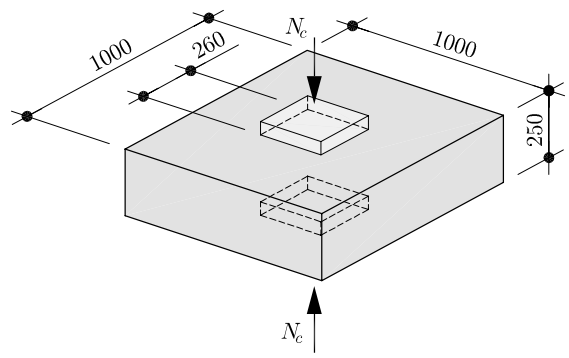

b

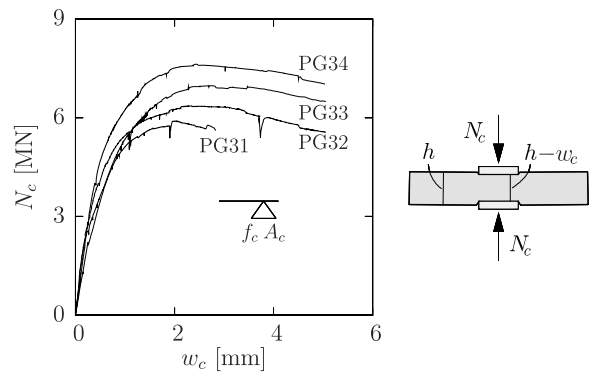

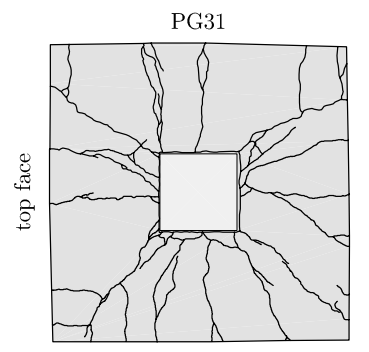
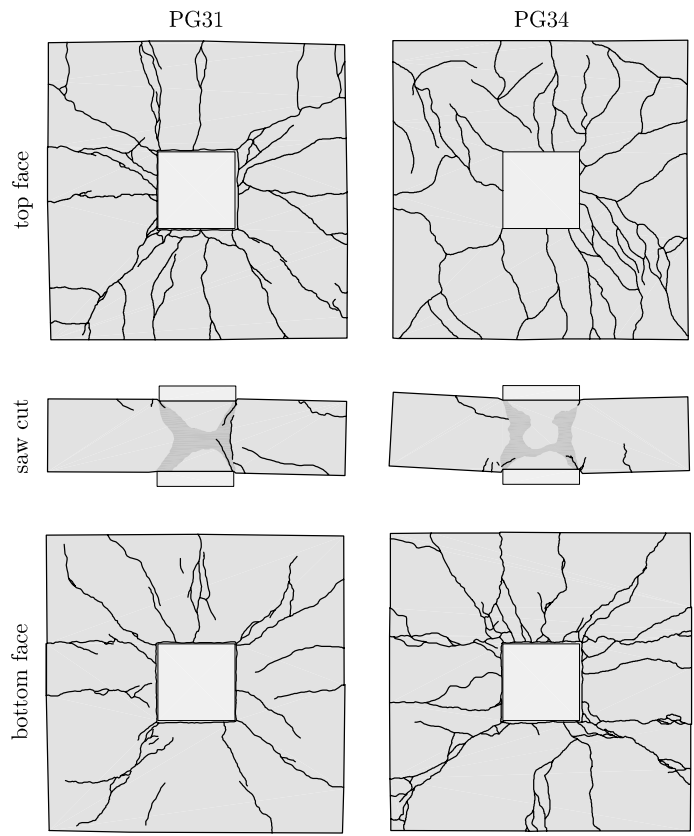

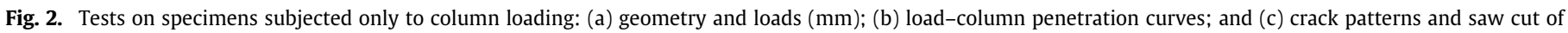
specimens PG31 and PG34 after testing.

\section{Experimental programme}

Six slab-column joints were tested within the experimental programme. Tests consisted of slabs where column loads where applied by means of steel plates $0.26 \times 0.26 \times 0.05 \mathrm{~m}$ placed on the top and on the bottom surface (Figs. 2(a) and 3(a)). Two sizes were selected for the slabs: $1.0 \times 1.0 \times 0.25 \mathrm{~m}$ for slabs subjected only to column loading $\left(N_{c}\right)$ and $3.0 \times 3.0 \times 0.25 \mathrm{~m}$ for slabs subjected to column and slab loading $\left(N_{c}, Q\right)$.

Specimens were only reinforced using flexural reinforcement with a nominal average effective depth $d=210 \mathrm{~mm}$ for top reinforcement and $d^{\prime}=30 \mathrm{~mm}$ for bottom reinforcement. No reinforcement linking the loading plates, nor shear reinforcement, was placed. The flexural reinforcement was arranged into four layers (two orthogonal layers per side of the slab). Four nominal ratios were used for the top reinforcement ( $\rho$ ranging between $0.25 \%$ and $1.50 \%)$ and three for the bottom reinforcement $\left(\rho^{\prime}\right.$ ranging between $0.18 \%$ and and $0.31 \%$ ), a complete summary is provided in Table 1 . After testing, the slabs were saw cut, allowing one to measure the actual effective depth of the slabs and to calculate the actual reinforcement ratios, see Table 1.

\subsection{Materials}

The slabs were cast using normal strength concrete. The compressive strength measured in cylinder (diameter $160 \mathrm{~mm}$, height $320 \mathrm{~mm}$ ) varied between $f_{c}=33.9$ and $51.6 \mathrm{MPa}$ (see Table 1). Maximum aggregate size was $16 \mathrm{~mm}$ for all specimens.

Hot-rolled reinforcement was used for top layers of specimens PG33, PG34, PG 13 and PG 35. The bottom reinforcement of all specimens as well as the top reinforcement of specimens PG31 and PG32 were cold-worked.

\subsection{Measurement and testing procedure}

Four specimens (PG31 to PG34) were only tested under column loading $\left(N_{c}\right)$, see Fig. 2(a). Column load was introduced through the steel plates using a Schenk Trebel machine with a maximum load capacity of $10 \mathrm{MN}$. Load was applied in two stages. First, the introduction of the load was force-controlled until a total force of 3.5 MN was applied. Thereafter, the test was displacementcontrolled. The test was stopped when the load decreased at least 
a

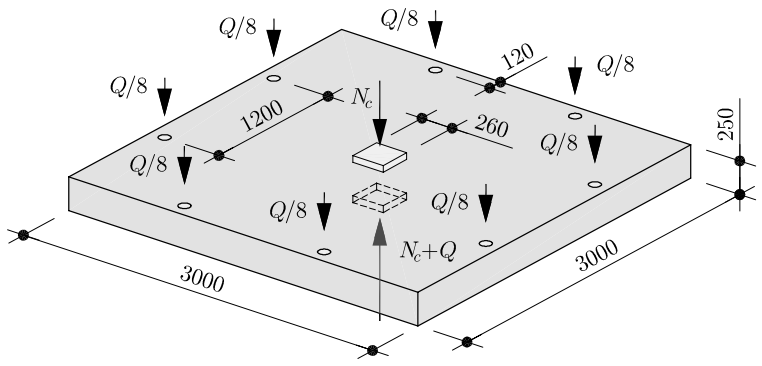

C

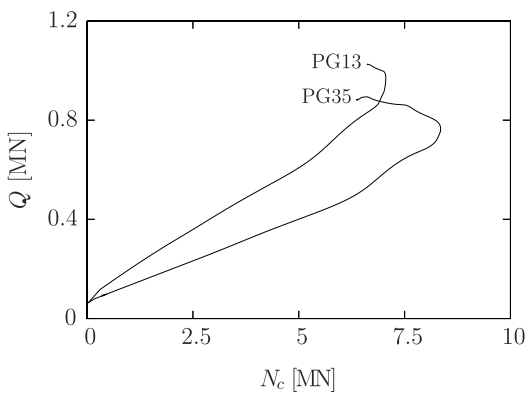

d

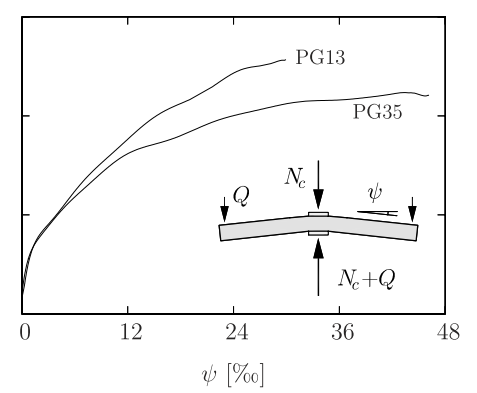

b

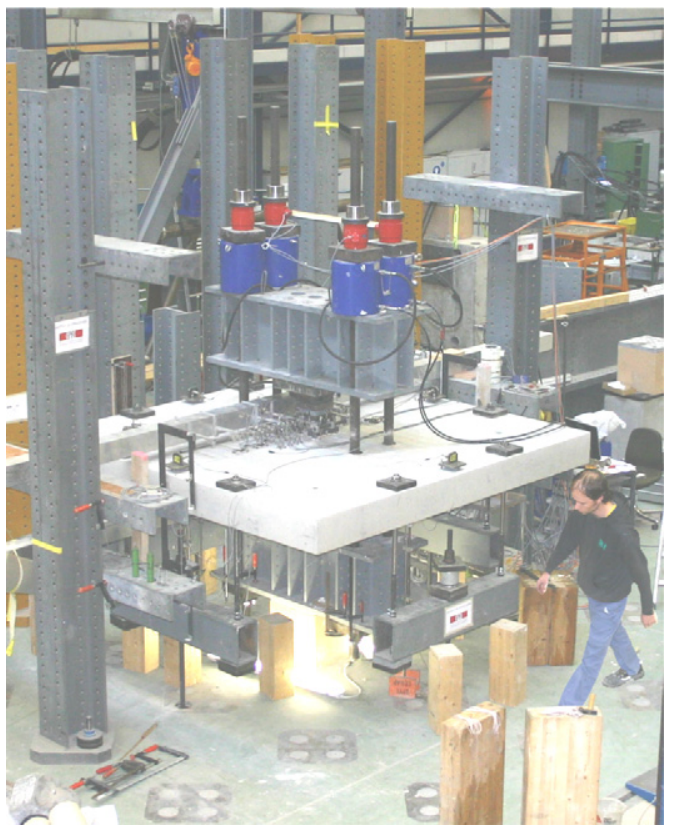

e
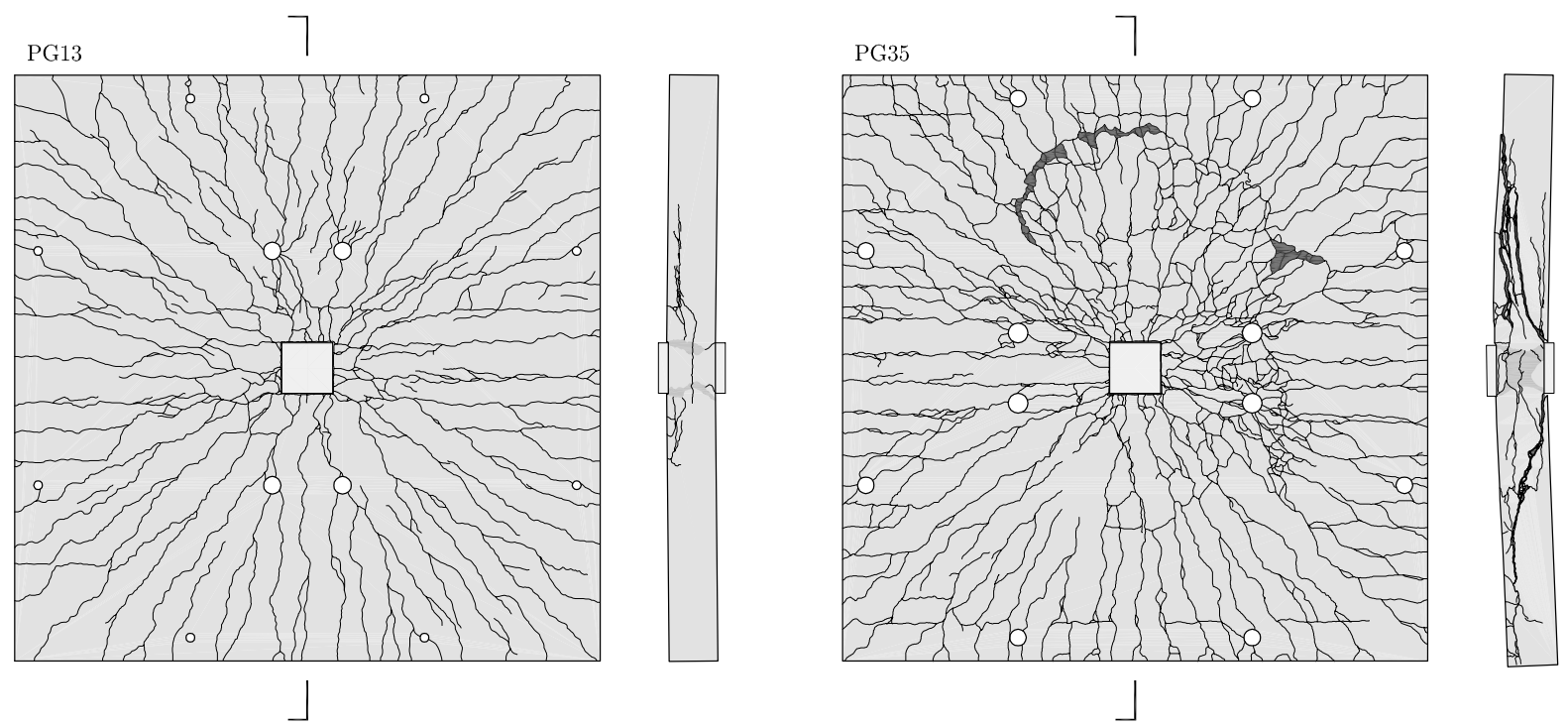

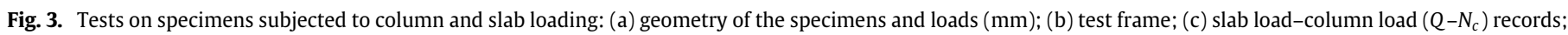
and (d) slab load-rotation $(Q-\psi)$ records; and (e) cracking pattern and saw cuts after testing.

Table 1

Summary of main properties and test results (failure loads refer to the column load $\left(N_{c, R}\right)$ measured when the maximum slab force $\left(Q_{R}\right)$ was reached).

\begin{tabular}{|c|c|c|c|c|c|c|c|c|c|c|c|c|}
\hline Specimen & $\rho(\%)$ & $\rho^{\prime}(\%)$ & $d(\mathrm{~mm})$ & $d^{\prime}(\mathrm{mm})$ & $f_{y}(\mathrm{MPa})$ & $f_{y}^{\prime}(\mathrm{MPa})$ & $f_{c}(\mathrm{MPa})$ & $E_{c}(\mathrm{GPa})$ & $N_{R, \text { test }}(\mathrm{MN})$ & $N_{R, \text { test }} / f_{c} A_{c}$ & $\mathrm{Q}_{R, \text { test }}(\mathrm{MN})$ & $w_{c R, \text { test }}(\mathrm{mm})$ \\
\hline PG31 & 0.271 & 0.271 & 203 & 40 & 500 & 500 & 50.7 & 33.7 & 5.90 & 1.72 & 0 & 2.05 \\
\hline PG32 & 0.347 & 0.270 & 204 & 40 & 500 & 500 & 51.2 & 33.7 & 6.35 & 1.84 & 0 & 2.32 \\
\hline PG33 & 0.804 & 0.275 & 200 & 35 & 510 & 500 & 51.6 & 33.7 & 6.97 & 2.00 & 0 & 2.77 \\
\hline PG34 & 1.571 & 0.275 & 200 & 35 & 551 & 500 & 51.6 & 33.7 & 7.62 & 2.19 & 0 & 2.43 \\
\hline PG13 & 0.822 & 0.181 & 195 & 38 & 538 & 531 & 33.9 & 34.0 & 6.61 & 2.88 & 1.03 & - \\
\hline PG35 & 0.785 & 0.306 & 205 & 37 & 510 & 500 & 49.6 & 33.7 & 6.58 & 1.96 & 0.894 & - \\
\hline
\end{tabular}

$10 \%$ with respect to the maximum recorded load. Penetration of the steel plates in each side of the slab was measured by means of four LVDT's placed on each loading plate.

In order to minimize irregularities on the contact between the steel plates and the slabs, contact surfaces were mechanically smoothed. In addition, a thin layer of plaster (0.5-1.0 mm thick) and a $0.1 \mathrm{~mm}$-thick PVC (PolyVinyl Chloride) sheet were placed between the plate and the slab. Prior to the beginning of the test, the specimens were preloaded to $1.5 \mathrm{MN}$ during $4 \mathrm{~h}$ in order to ensure perfect contact between the plates and the slab.

Two specimens (PG13 and PG35) were tested to investigate the interaction between column loading $\left(N_{c}\right)$ and bending of the 
slab (load $Q$ ). Loads were introduced with the arrangement given in Fig. 3(a) through a stiff testing frame [7,8] shown in Fig. 3(b). Specimen PG35 was provided with the same interface as tests PG31 to PG34. On the contrary, for specimens PG13 column loads were applied through a thin layer of mortar without a PVC sheet between the surfaces (which increased the friction on the load surface) to investigate on the influence of contact surface properties.

\section{Experimental results}

\subsection{Specimens subjected exclusively to column loading}

First cracks appeared in the radial direction for all specimens at a load of approximately $2.1 \mathrm{MN}$. Thereafter, additional cracks developed in the radial direction with crack distance and opening influenced by the top and bottom reinforcement ratios. Cracks continued to open with increasing load until yielding of the reinforcement developed at one of the corners of the support plate in the bottom reinforcement (side with lowest reinforcement). Thereafter, strains localized at this crack, leading to a rotation of the slab upwards and to a progressive decrease of the recorded column load. Fig. 2(c) shows the crack patterns and saw cuts after testing of specimens PG31 and PG34 (with the lowest and highest top reinforcement ratios respectively).

Fig. 2(b) plots the applied load versus column penetration records $\left(N_{c}-w_{c}\right)$. The figure shows that after reaching the maximum strength $\left(N_{c, R}\right)$ the behaviour was rather ductile even for fairly low reinforcement ratios. This indicates, together with the fact that the maximum load was significantly larger than that of the uniaxial compressive strength of concrete (Table 1 ), that failure zones were significantly confined by the available reinforcement of the slab.

\subsection{Specimens subjected to columns and slab loading}

Tests PG13 and PG35 developed both a plastic mechanism with yielding of the top reinforcement. No cracks were on the contrary visible on the bottom face. The plastic mechanisms consisted of a single yield line (developed by the layer of reinforcement with smaller effective depth). After development of the yield line, slab load $Q$ could be increased by reducing the column load $N_{c}$, see Fig. 3(c).

The slabs developed significant rotations around the column during the plastic phase with large crack widths concentrated at the yield line. Such rotations led to local spalling of the concrete on the bottom face for specimen PG35 near the column region. After large deformations, the specimens eventually punched. This is explained because the ability of concrete to transfer shear reduces with increasing crack widths, and is consistent with experimental observations of other researchers $[8,9]$. Contrary to specimens subjected only to column loading, the failure mechanism occurred in this case with the specimens developing rotations downwards.

It can be noted that, as for tests subjected only to column loading, the concrete stresses under the loading plates exceeded significantly the uniaxial compressive strength of concrete (see Table 1). Confinement provided by the flexural reinforcement was thus also effective even for the very large transverse strains developed by concrete at the column load plates (estimated around $5 \%$ for the measured rotations).

With respect to the ductile behaviour observed for the tests, it is interesting to note that similar specimens but tested with no or limited column load showed brittle punching shear as the governing failure mode. More details can be found on [7]. a
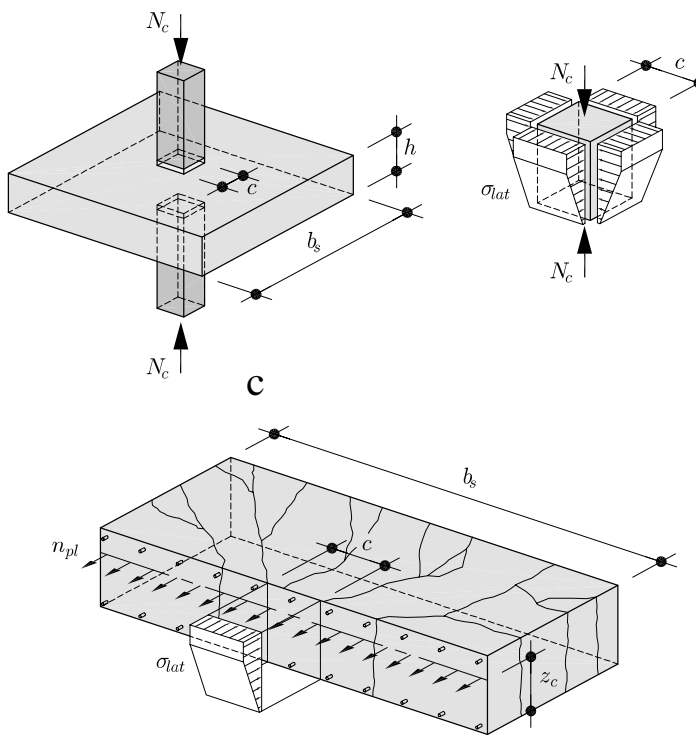

Fig. 4. Geometry and stress field in a slab-column joint subjected to column loads: (a) geometry and loads; (b) stress field in the inner prism; and (c) in the surrounding region of the slab.

\section{Physical model for joints subjected exclusively to column loading}

The behaviour of slab-column joints for specimens subjected exclusively to column loading can be investigated on the basis of a concrete prism subjected to vertical compression stresses due to column loading and to transverse confinement stresses of the slab, see Fig. 4. Confinement stresses are originated by the top and bottom reinforcement which restrains the transverse expansion of concrete under vertical compression stresses. As experimentally observed, confinement stresses increase the strength and ductility of concrete between column loads with respect to the uniaxial behaviour of concrete.

Such a model can be developed for a flat slab by splitting it into two regions: a concrete prism between column plates (Fig. 4(b)) and the outer region of the slab (Fig. 4(c)). The inner concrete prism ensures transfer of column loads whereas the rest of the slab provides confinement for the inner concrete part.

\subsection{Behaviour and strength of the concrete prism}

The compressive strength of the concrete prism carrying column loads depends on both the transverse strains and stresses applied to it. With respect to the influence of confinement stresses $\left(\sigma_{\text {lat }}\right)$ it has been experimentally shown that they increase the vertical compressive strength of concrete $\left(f_{c c}\right)$ with respect to its uniaxial strength $\left(f_{c}\right.$, accounting for concrete cylinder size [7]). This increase is usually assessed by means of the following linear formula:

$f_{c c}=f_{c}+k \sigma_{\text {lat }}$.

Fig. 5(b) compares Eq. (2) to a set of availableexperimental data (discussed in Appendix of this paper) showing good agreement. Other expressions (root-type) to describe the influence of confinement stresses on concrete strength are also discussed in Appendix.

With respect to the influence of transverse strains, their influence can be investigated on the basis of the vertical stresstransverse strain curve $\left(\sigma_{3}-\varepsilon_{1}\right)$ of concrete (see [16]). Such an approach is shown in Fig. 6(a), where specimens subjected to 
a

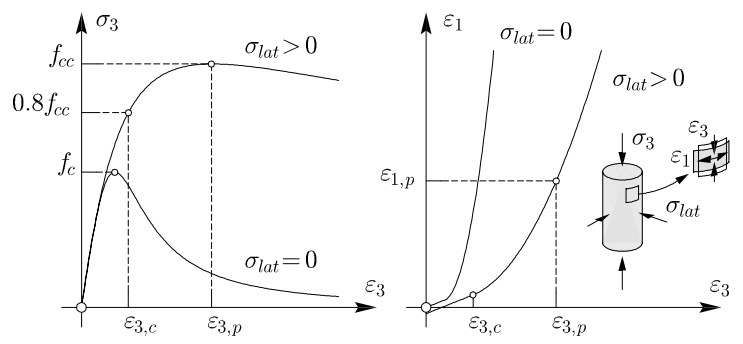

b

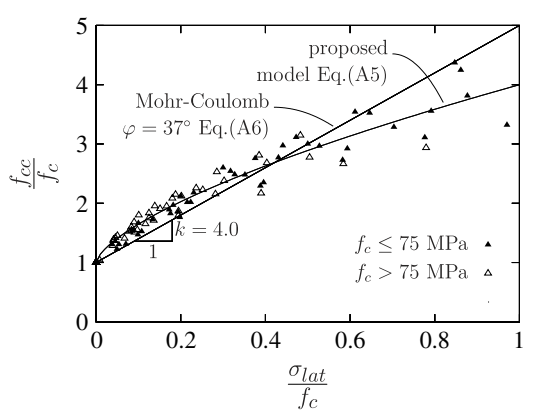

Fig. 5. Effect of the confinement of concrete: (a) $\operatorname{confined}\left(\sigma_{\text {lat }}>0\right)$ and unconfined $\left(\sigma_{\text {lat }}=0\right)$ concrete behaviour (stress versus longitudinal strain relationship; and transverse expansion); and (b) ratio between confined and unconfined strength as a function of confinement stresses (tests from [10-15]).

imposed transverse strains crush at lower strengths than corresponding specimens without imposed strains. The reduction on the strength is justified by the fact that specimens with imposed transverse strains exhibit the same state of stresses and transverse strains than specimens without imposed strains during their compression softening branch. Such behaviour has widely been confirmed experimentally for panels or specimens under nonconfined conditions (see for instance $[17,18]$ ). A comparison of

$\mathrm{a}$

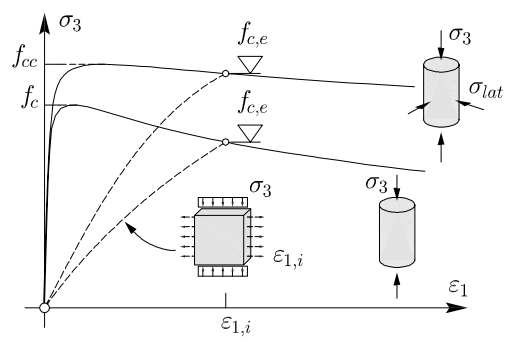

C

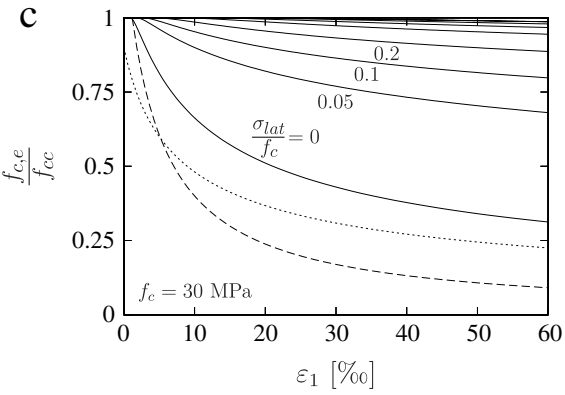

expressions based on fitting to test results $[17,18]$ for unconfined specimens to the compression softening approach [16] shows similar results (refer to Fig. 6(b), compression softening behaviour calculated using the formulas given in Appendix).

Based on this approach, the reduction of concrete strength depends not only on the imposed transverse strains but also on the shape (brittleness) of the compression softening behaviour of concrete (Fig. 6(b)). As a consequence, for confined specimens, the strength reduction due to a given imposed transverse strain is significantly lower than the corresponding for an unconfined specimen. This is justified because the slope of the softening branch in the $\sigma_{3}-\varepsilon_{1}$ curve decreases with respect to non-confined specimens (less brittle behaviour), refer to Fig. 6(c).

It should be noted that confinement compression stresses can be developed by concrete even if an imposed positive transverse strain is applied. This behaviour can be explained with the analogy shown in Fig. 7, where a volume of soil is retained by two lateral hinged walls anchored by a tension tie (Fig. 7(a)). In the elastic phase, any lateral movement of the soil leads to a reduction of the confining pressure (force of the tie), refer to vector A in Fig. 7(b). The confining pressure is furthermore sensitive to changes in the length of the tie (such as changes in temperature or relaxation losses of the tie). However, as lateral expansion progress, the soil reaches its plastic active state and the confining pressure of the soil (force in the tie) remains constant even for increasing lateral displacements or for changes in the length of the tie, refer to vector B in Fig. 7(b). The region of a slab between columns actually behaves after crushing in this manner (as the plastic active state of soil) with the confinement pressure governed by equilibrium conditions even for significant positive transverse strains (activation of the confining pressure for a given column load according to Eq. (2)).

The $\sigma_{3}-\varepsilon_{1}$ behaviour is also shown in Fig. 6(c) as a function of the confinement stresses for a concrete with a uniaxial compressive strength of $30 \mathrm{MPa}$ and in Fig. 6(d) to a concrete of $51.3 \mathrm{MPa}$ (average strength of the test series presented within this paper). It can be seen that, even for rather limited confinement

b

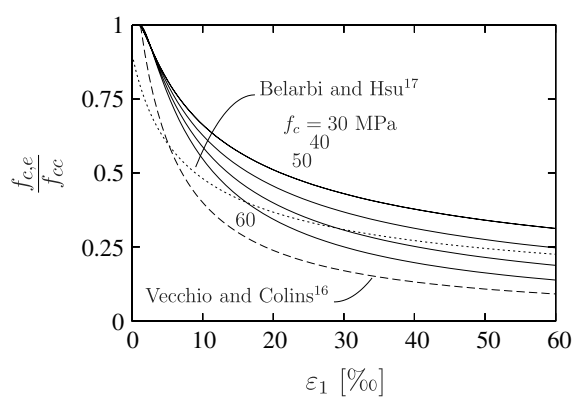

d

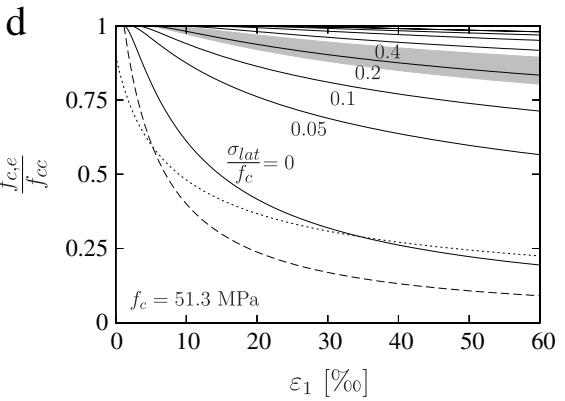

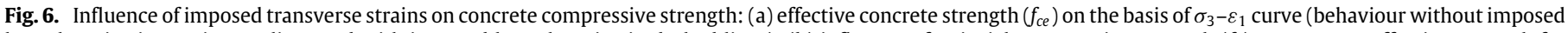

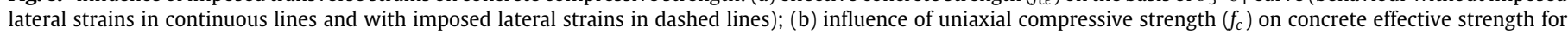

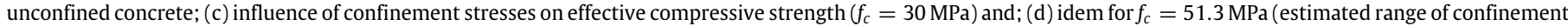
stresses for tests PG31 to PG34 indicated in the shaded region). 
a

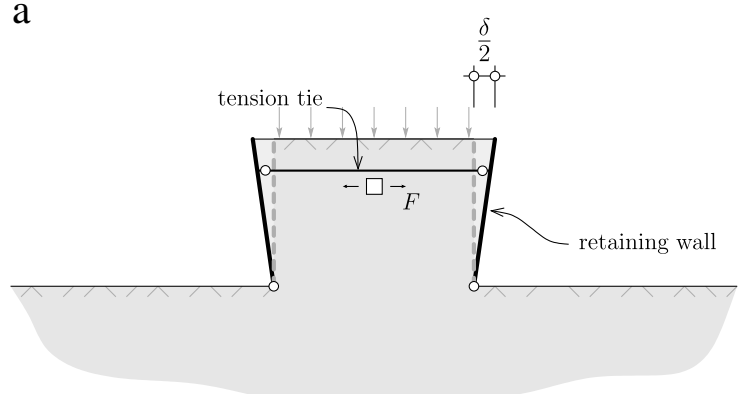

b

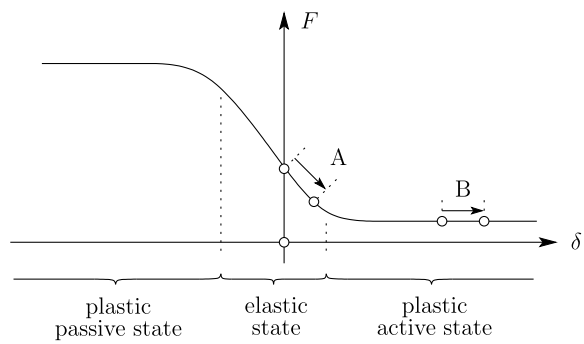

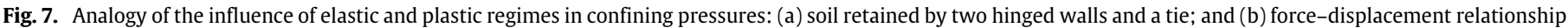
for elastic and plastic states.

stresses, the increase on the ductility is significant. This fact is particularly relevant with respect to slab-column joints, where confinement stresses can be relatively high and the behaviour may be significantly ductile (close to a perfectly plastic behaviour). For instance, for the specimens tested within this research, the estimated increase is shown in the shaded region of Fig. 6(d) (corresponding to a calculated confinement stresses according to the physical model presented in the following).

\subsection{Confinement stresses provided by the surrounding slab}

The maximum confinement stress that the slab surrounding the concrete prism (Fig. 4(c)) can provide can be calculated assuming full yielding of the reinforcement [19] and neglecting concrete contribution in tension for design purposes:

$n_{p l}=\omega_{t} \cdot h \cdot f_{c} \frac{b_{s}}{c}$

where $\omega_{t}$ refers to the total mechanical reinforcement ratio of the slab:

$\omega_{t}=\frac{\left(\rho+\rho^{\prime}\right) f_{y} d}{f_{c} h}$

where $\rho$ and $\rho^{\prime}$ refer to the top and bottom reinforcement ratios respectively, $d$ is the effective depth of the member, $f_{y}$ is the reinforcement yield strength (assumed to be the same for top and bottom layers), $b$ is the width of the slab and $c$ is the column dimension. The confinement force provided by the surrounding concrete is in equilibrium with the resultant of the confinement stresses at the inner prism. Thus $n_{p l}=\int_{0}^{h} \sigma_{\text {lat }} \mathrm{d} z$ (equilibrium of forces) and the position of the stress resultant (equilibrium of moments) is placed at:

$z_{c}=\frac{\rho d+\rho^{\prime} d^{\prime}}{\rho+\rho^{\prime}}$.

With respect to the distribution of confinement stresses over the depth of the member, several stress profiles are possible, see Fig. 8. The simpler one corresponds to a linear distribution when the stress remains smaller than the concrete uniaxial strength $\left(f_{c}\right)$, see Fig. 8(a). Another profile corresponds to a bilinear distribution with a plateau at $f_{c}$ (Fig. 8(b)). The condition for both profiles of keeping stresses below the concrete uniaxial strength has to be required since the concrete surrounding the inner prism is not confined in the out-of-plane direction.

Assuming the previously introduced laws, the stress profile can be determined as follows if concrete stresses remain below concrete uniaxial strength:

$\sigma_{\text {lat }, 2}=n_{p l} \frac{6 z_{c}-2 h}{h^{2}} \leq f_{c}$.

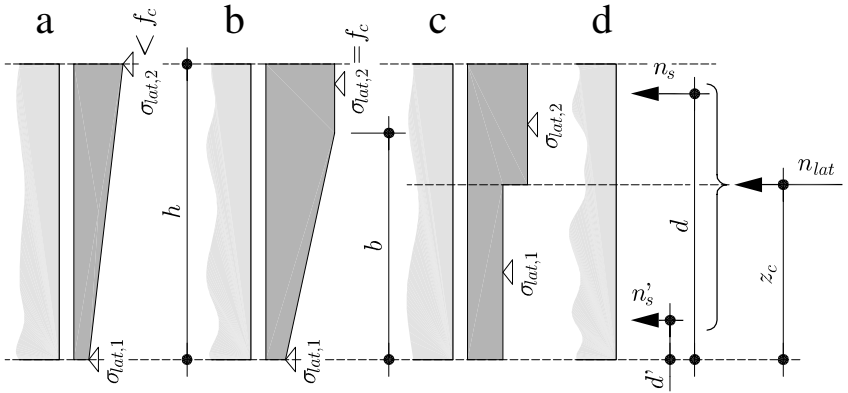

Fig. 8. Stress profiles over the cylinder: (a) linear; (b) bilinear; (c) simplified and (d) resultants.

For other cases, the following relationships apply:

$\sigma_{\text {lat }, 1}= \begin{cases}n_{p l} \frac{4 h-6 z_{c}}{h^{2}} & \text { if } \sigma_{\text {lat }, 2}<f_{c} \\ f_{c}-\frac{2}{3} \cdot \frac{\left(f_{c} h-n_{p l}\right)^{2}}{f_{c} h^{2} / 2-n_{p l} z_{c}} & \text { if } \sigma_{\text {lat }, 2}=f_{c}\end{cases}$

with:

$b=2 \frac{f_{c} h-n_{p l}}{f_{c}-\sigma_{\text {lat } 1}} \leq h$.

In some cases, with an extremely low reinforcement on one side, $\sigma_{\text {lat }, 1}$ or $\sigma_{\text {lat }, 2}$ may potentially become negative. This solution, without physical meaning, can be avoided by reducing iteratively the yield stress of the strongest reinforcement layer in order to satisfy the conditions $\sigma_{\text {lat }, 1}=0$ (this is for instance governing for test PG34).

\subsection{Concrete strength in the inner concrete prism accounting for non- uniform confinement stresses}

The increase on concrete strength with a confinement pressure can be estimated on the basis of the theory of plasticity $[10,20]$. For instance, in cases where the confinement pressure is uniform over the height of a concrete cylinder and if a Mohr-Coulomb yield criterion is assumed, concrete strength results:

$f_{c c}=f_{c}+k \cdot \sigma_{\text {lat }}=f_{c}+\frac{1+\sin \varphi}{1-\sin \varphi} \sigma_{\text {lat }}$

where $\varphi$ is the friction angle of concrete. Assuming a value of $\sim 37^{\circ}$ (usual cases $[10,20]$ ), coefficient $k$ results $k=4.0$, which is in rather good agreement with test results (see Fig. 5).

Applications of the theory of plasticity to concrete members where confinement is not uniform over the height of the member (refer to Fig. 8) have not been found in the scientific literature. This case, which is relevant for the present study, will be investigated, for the axis-symmetric case, in the following. The problem will be solved on the basis of the following assumptions:

- An axis-symmetric concrete cylinder with its height at least double its width is considered. The cylinder is subjected to 
a

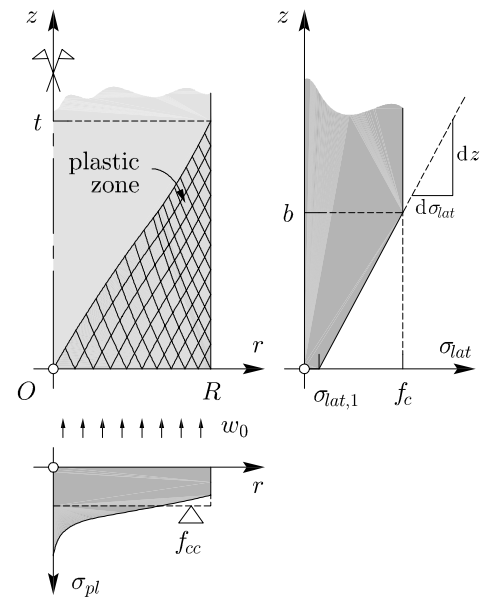

$\mathrm{b}$
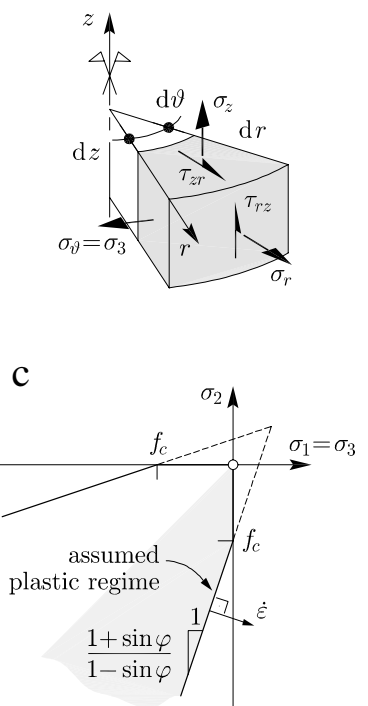

Fig. 9. Plastic analysis for a cylinder subjected to non-uniform confinement: (a) geometry and boundary conditions considered; (b) stress equilibrium in axis-symmetric geometry; and (c) Mohr-Coulomb yield criterion without tensile strength.

non-uniform confinement stresses $\left(\sigma_{\text {lat }}(z)\right)$ and to a relative displacement $\left(w_{0}\right)$ between the top and bottom faces, refer to Fig. 9(a, b).

- A Mohr-Coulomb yield criterion without tensile strength is used assuming an associative flow rule (Fig. 9(c)).

- The problem is solved using the characteristic lines method ( $\alpha, \beta$-lines) and a numerical approach for solving the differential equations defining the stress field [21-23].

This method allows calculating the plastic strength of the cylinder (refer to Fig. 10). For comparison to uniformly confined cylinders, the average vertical stress $\left(f_{c c}\right)$ and the average confinement stress $\left(\sigma_{\text {lat }, m}\right)$ on the plasticized height $(t)$ will be used in the following.
The average vertical stress can be calculated by dividing the plastic strength of the cylinder by the surface of the support plates and the average confinement stress by using:

$$
\begin{aligned}
\sigma_{\text {lat }, m}= & \sigma_{\text {lat }, 1}+\frac{\sigma_{\text {lat }, 2}-\sigma_{\text {lat }, 1}}{2 b} t \\
& -\frac{\left(\sigma_{\text {lat }, 2}-\sigma_{\text {lat }, 1}\right)(t-b)}{2 b t}\langle t-b\rangle
\end{aligned}
$$

where function $\langle x\rangle$ is equal to $x$ if $x>0$ and to 0 otherwise.

The increase of the concrete's strength for such cases (nonuniform confinement) can be written in a similar way as Eq. (7) but using the following parameter $k_{m}=\left(f_{c c}-f_{c}\right) / \sigma_{\text {lat }, m}$. Fig. $10(\mathrm{~g})$ shows that coefficient $k_{m}$ is little sensitive to the shape of the confinement pressures, and that a value $k_{m}=4.0$ is still sufficiently accurate for most cases. For preliminary design purposes, selecting a value $t=1.25 R$ is also sufficiently accurate (error in $\sigma_{p l, m}$ smaller than $\pm 4 \%$ ). More refined values can be obtained through the diagrams (refer to Fig. 10(f-g)). This approach can also be used to square prisms by introducing $R=c / \sqrt{\pi}$ and a height of the plastic zone equal to $t=0.7 c$.

\subsection{Consideration of reinforcement linking upper and lower columns}

In case vertical reinforcement bars connect the upper and lower columns (Fig. 1(a, c, d, e)) a fraction of the load can be transmitted by them (refer to Eq. (2)). According to a plastic approach, this contribution can be estimated as:

$N_{s, R}=f_{y} A_{s}$.

With reference to the vertical strains measured in the tests presented in this paper, this approach would be completely justified. For instance (refer to Fig. 2(b) and Table 1) column penetration at concrete crushing was between 2.0 and $2.7 \mathrm{~mm}$ for all specimens, which (for a slab thickness of $250 \mathrm{~mm}$ ) corresponds to a vertical average strain larger than $8.0 \%$ (more than 3 times the strain of ordinary reinforcing steel at yielding).
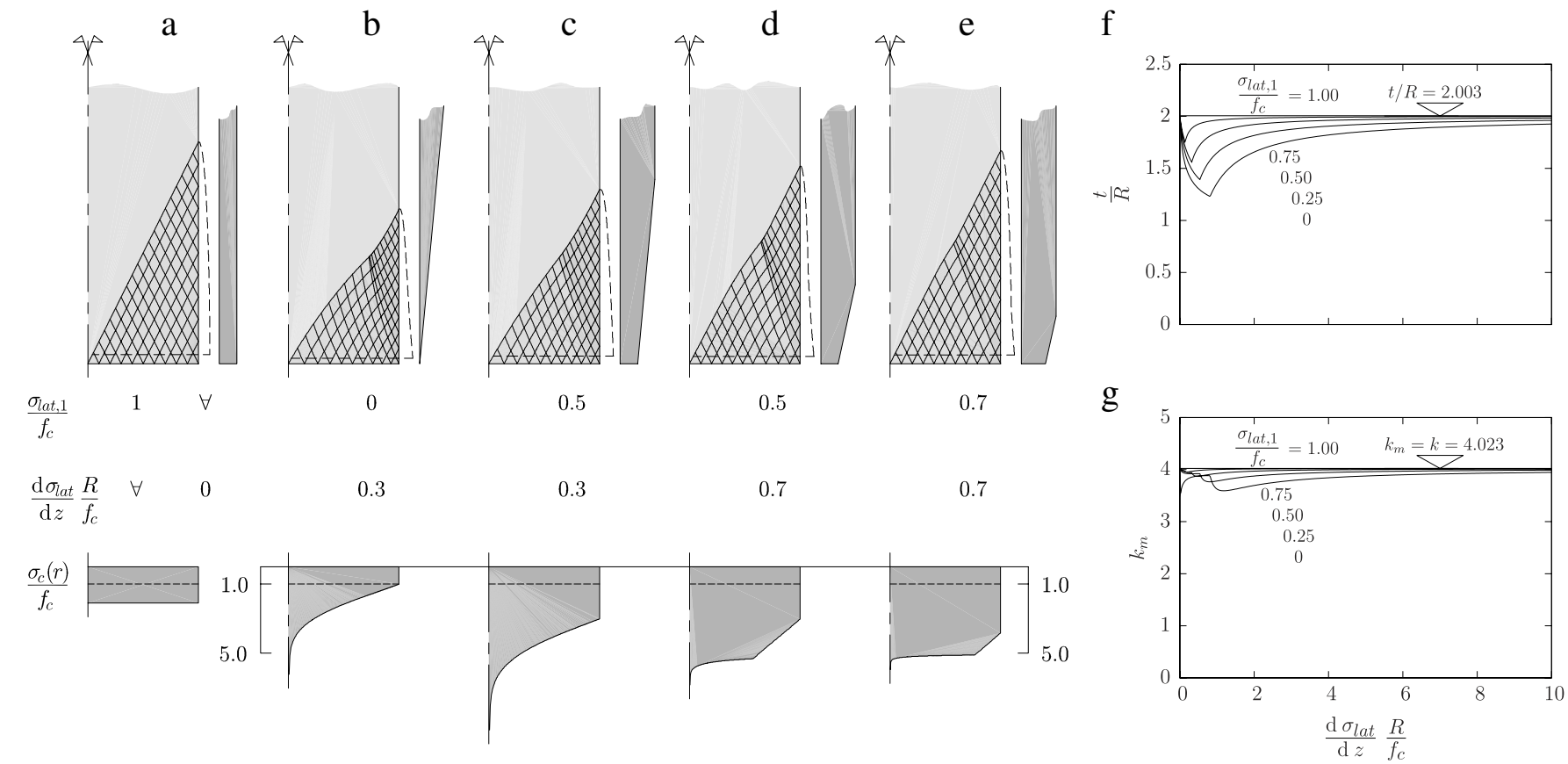

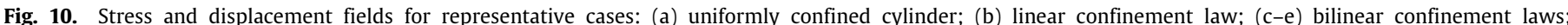
(f) and (g) ratio $t / R$ and coefficient $k_{m}$ as a function of the confinement stress profile. 
a

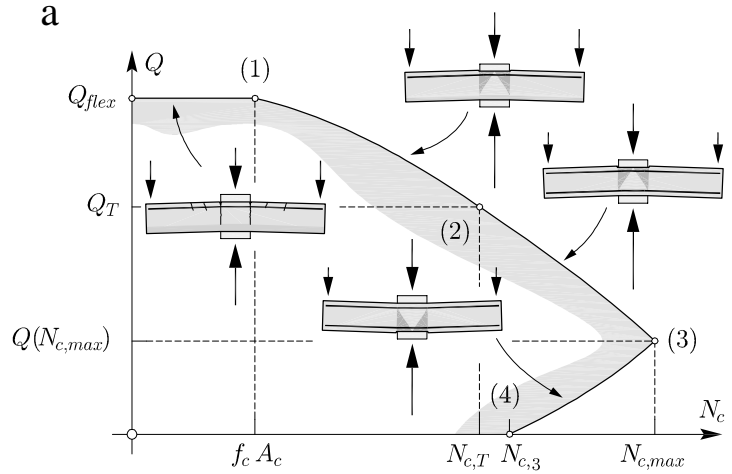

b

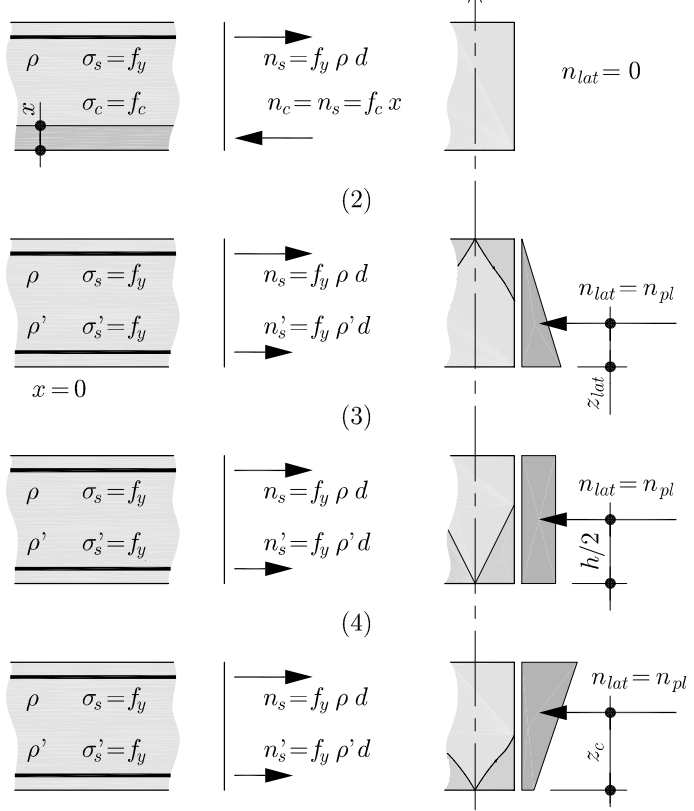

Fig. 11. Slab load-column load interaction diagram: (a) shape and characteristic points; and (b) stress field and failure zone for characteristic points.

\section{Behaviour of slabs subjected to column and slab loading}

In actual flat slabs, slab-column joints are subjected to both loads coming from the columns $\left(N_{c}\right)$ and to loads applied to the slab $(Q)$ as shown in Fig. 3(a). In the case where a fraction of the flexural reinforcement is required for confining the concrete of the slab between columns (concrete crushing) the full flexural strength (assessed for instance by means of the conventional yield line theory) cannot be developed. On the contrary, for moderate levels of column loading (stresses due to column loading below the uniaxial compressive strength of concrete) no confinement is required and the full flexural strength is available.

The interaction between column and slab loading can be investigated on the basis of a $Q-N_{c}$ interaction diagram as shown in Fig. 11(a). Such diagram is composed of a series of regimes, where some characteristic points are:

- Crushing of the concrete with no loads applied to the slab (point 4 in Fig. 11). Details on this case were given in the previous section.

- Crushing of concrete under maximum uniform confinement (with yielding of both reinforcements, point 3 in Fig. 11). This leads to the maximum strength in terms of column loading, and can be calculated by equilibrium conditions as:

$$
N_{c, \max }=A_{c}\left(f_{c}+4.0 \frac{n_{p l}}{h}\right)-Q\left(N_{c, \max }\right)
$$

Table 2

Comparison between measured and calculated failure loads and column penetrations for the different proposed models.

\begin{tabular}{llll}
\hline & & \multicolumn{2}{l}{ Rigid plastic model } \\
\cline { 3 - 4 } & & $t$ and $k$ var. & $t$ and $k$ const. \\
\hline Specimen & $N_{R, \text { test }}(\mathrm{MN})$ & $N_{R, \text { calc }}(\mathrm{MN})$ & $N_{R, \text { calc }}(\mathrm{MN})$ \\
\hline PG31 & 5.90 & $5.71(1.03)$ & $5.75(1.03)$ \\
PG32 & 6.35 & $6.02(1.06)$ & $5.94(1.07)$ \\
PG33 & 6.97 & $7.30(0.95)$ & $7.04(0.99)$ \\
PG34 & 7.62 & $7.69(0.99)$ & $7.70(1.00)$ \\
\hline & Average: & 1.01 & 1.02 \\
& COV: & 0.04 & 0.03 \\
\hline
\end{tabular}

where:

$$
Q\left(N_{c, \max }\right)=2 n_{p l} \frac{z_{c}-h / 2}{b_{q} / c-0.5}
$$

where $z_{c}$ is calculated using Eq. (5) and $b_{q}$ is the distance of the applied loads to the bending yield line (this value will be defined for practical applications in section "design proposal").

- Maximum slab load at which the bottom reinforcement still yields at concrete crushing (point 2 in Fig. 11). It can be calculated assuming the confinement stress distribution of Fig. 11(b) (which maximizes the flexural lever arm), leading to:

$Q_{T}=2 n_{p l} \frac{z_{c}-z_{\text {lat }}}{b_{q} / c-0.5}$

where $z_{\text {lat }}$ refers to the distance between the bottom slab face and the resultant of confinement stresses $\left(n_{l a t}=n_{p l}\right)$. The corresponding column load is thus:

$N_{c, T}=A_{c}\left(f_{c}+k_{m} \sigma_{\text {lat }, m}\right)$

where the average confinement stress can be calculated from Eq. (8) with the distance $t$ and the corresponding distribution of $n_{\text {lat }}$. The values of the height $t$ and of the coefficient $k_{m}$ can be obtained through the diagrams of Fig. 10(f-g). Alternatively the simplified values can be used $\left(k_{m}=4.0\right.$ and $\left.t=0.7 c\right)$.

- Development of a flexural mechanism, without crushing of the concrete between column loads (point 1 in Fig. 11). This regime governs if the concrete stress between column loads is lower or equal than the uniaxial compressive strength of concrete. Conventional yield line theory can be used to assess the strength of this regime.

\section{Comparison between the proposed model and the experi- mental results}

\subsection{Specimens subjected exclusively to column loading}

The results in terms of column load versus column penetration are compared to the test results in Fig. 12(a). The plots show very good agreement with the tests for the crushing strength. The accuracy of the plastic approach is justified by the very ductile behaviour of concrete under confinement stresses as previously explained.

The column penetration can be estimated using the approach presented in this paper assuming axis-symmetric conditions and accounting for compatibility conditions at the interface between the inner concrete prism and the surrounding concrete. This approach (leading to a nonlinear analysis) is thoroughly described in Guidotti [19] for the stress-strain law detailed in Appendix of this paper. Its results are compared to tests measurements in Fig. 12(a) and Table 2 with an excellent agreement in terms of strength, column penetration and post-peak behaviour. 

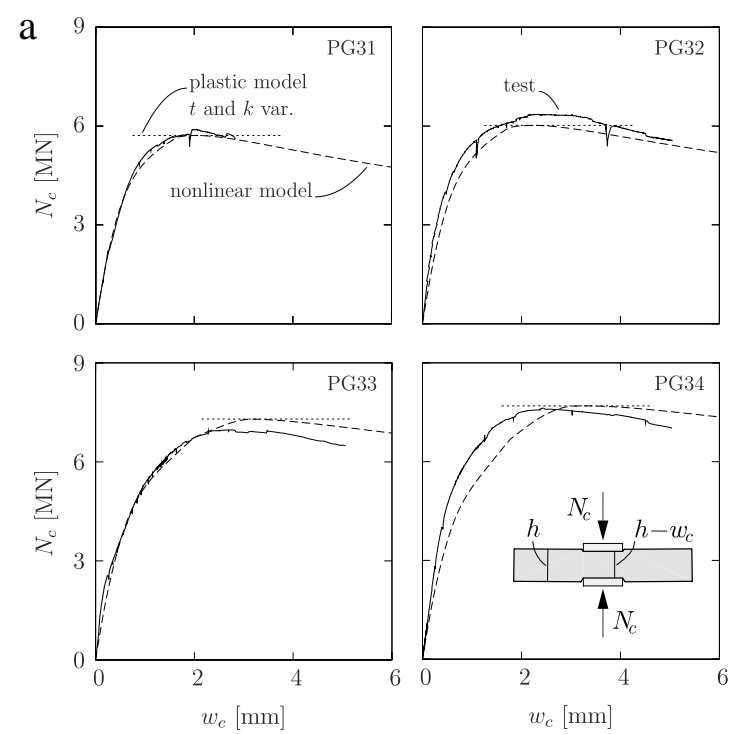
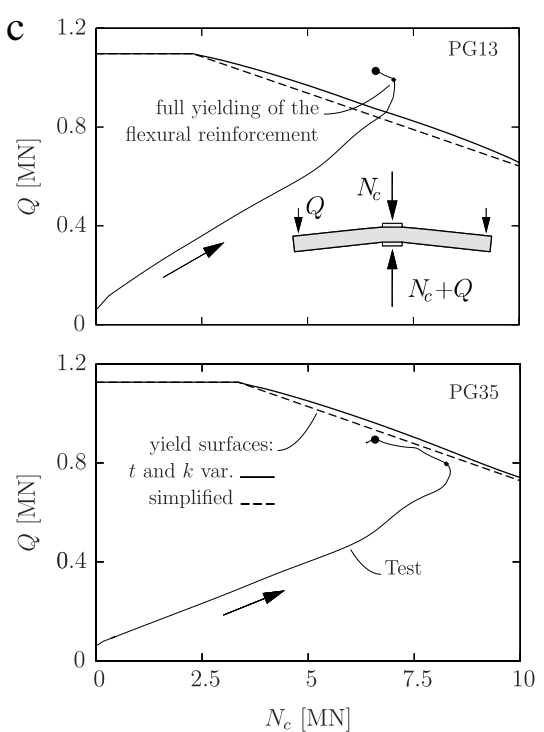

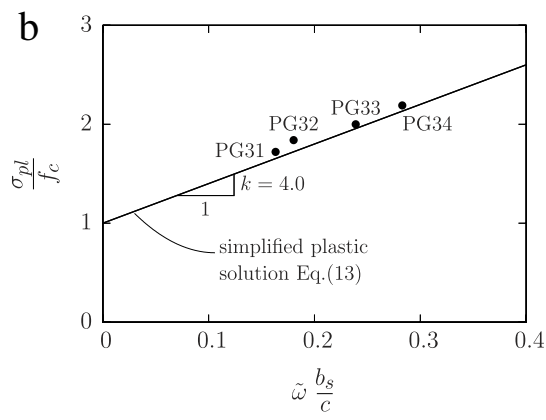

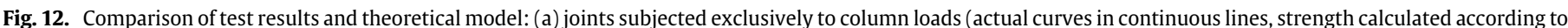

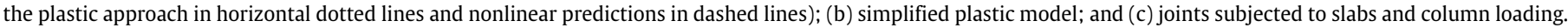

\subsection{Specimens subjected to column and slab loading}

Fig. 12(b) plots the recorded slab load-column load diagrams (solid lines) and compares them to the yield surfaces determined on the basis of the formulas introduced in the previous section $\left(b_{q}=860 \mathrm{~mm}\right.$ ). It can be noted that the plastic regime (decreasing column load with increasing slab load) is satisfactorily reproduced, with a good estimate of the strength and $Q-N_{c}$ slope after yielding. For specimen PG13 the strength is somewhat underestimated. This is explained because column loads were applied through a thin layer of mortar without the PVC sheet between the surfaces, which increased friction on the load surface with respect to test PG35 (thin layer of plaster plus PVC sheet). A discussion on the practical implications of the interface properties can be found elsewhere [19].

\section{Design proposal}

For practical applications, a simplified distribution of confinement stresses around the concrete confined part can be assumed. For instance, it is convenient to assume two zones of constant confinement stress (refer to Fig. 8(c)), whose integral respects the value and position of the stress resultant. In so doing for slabs subjected exclusively to column loading (point 4 of Fig. 11), the average confinement stress $\left(\sigma_{\text {lat }, m}\right)$ can be calculated over a height $t=1.25 R \leq h$ leading to the following crushing strength (assuming $k_{m}=4.0$ as previously justified):

$\sigma_{p l}=f_{c}+4.0 \tilde{\omega}_{t} f_{c} \frac{b_{s}}{c} \leq 5.0 f_{c}$ where $\tilde{\omega}_{t}$ refers to an effective mechanical reinforcement ratio accounting for the actual reinforcement distribution:

$\tilde{\omega}_{t}=\omega_{t}\left(\frac{h-2 z_{c}}{z_{c}}+1-h \frac{h-2 z_{c}}{z_{c}\left(h-z_{c}\right)}\left\langle 1-\frac{z_{c}}{t}\right\rangle\right)$.

In the case where a set of loads $(Q)$ are applied to the slab, the position of the confining stresses resultant $\left(z_{\text {lat }}\right.$, see Fig. $\left.11(\mathrm{~b})\right)$ is no longer coincident with $z_{c}$ (position of confining stress resultant for a slab with no loads applied on it). However, Eqs. (14) and (15) still remain valid and can be used by selecting a suitable position for the confining stresses resultant $\left(z_{\text {lat }}\right)$ maximizing the flexural lever arm. For cases between points 1 and 2 of Fig. 11, it is sufficiently accurate for design purposes to adopt $z_{\text {lat }}=h / 3$. This value can be introduced into Eq. (15) by replacing $z_{c}=h-z_{\text {lat }}=2 h / 3$ (crushing on the top side of the slab as shown in Fig. 11). In addition, the actual width of the slab $\left(b_{s}\right)$ in Eq. (14) has to be replaced by the width of the slab necessary to equilibrate the confining stresses of the inner prism. This term, named $b_{n}$ in the following, can be calculated as:

$b_{n}=\frac{m_{p l} b_{s}-Q / 2 b_{q}}{m_{p l}-\omega f_{c} h\left(z_{c}-z_{\text {lat }}\right)}$

where $m_{p l}$ refers to the plastic bending moment calculated considering only the top (flexural) reinforcement.

For the other regimes of the diagram of Fig. 11, a similar approach can be adopted. To do so, Eq. (16) can be used to calculate $z_{\text {lat }}$ by assuming $b_{n}=b_{s}$. This value of $z_{\text {lat }}$ replaces the term $z_{c}$ in Eq. (15) when failure occurs with crushing at the bottom side of the slab (refer to regime between points 3 and 4 of Fig. 11). 

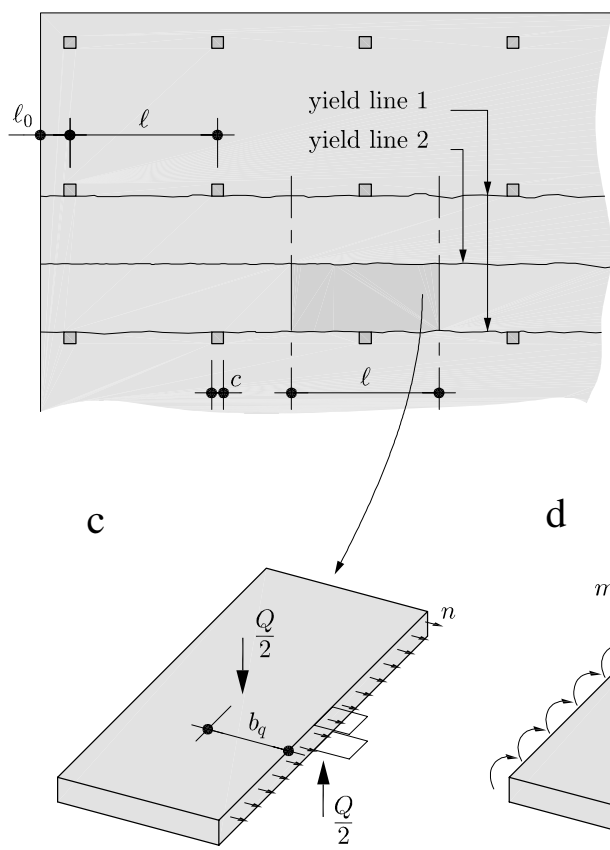

b

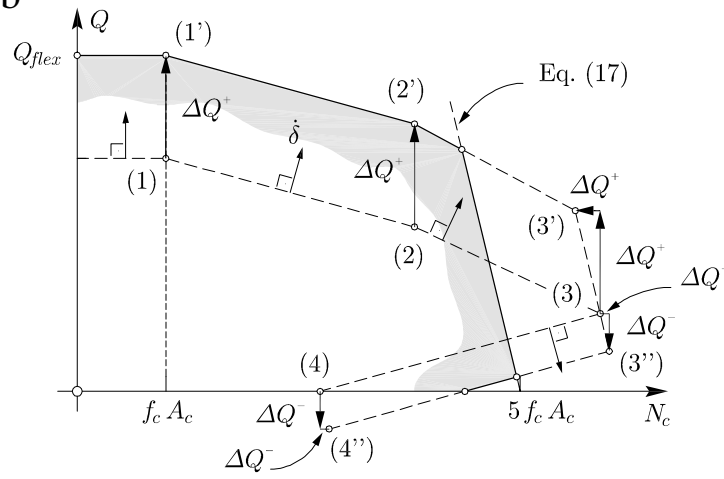

d

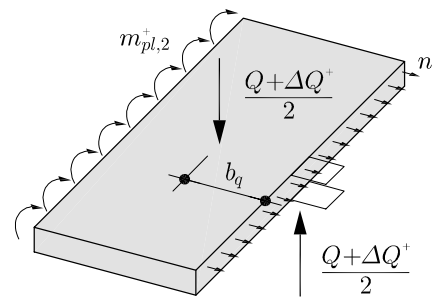

e

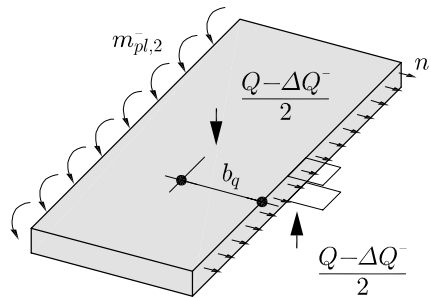

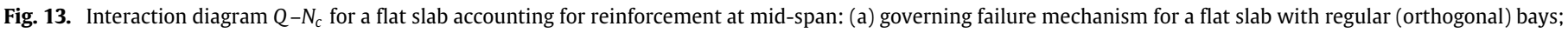

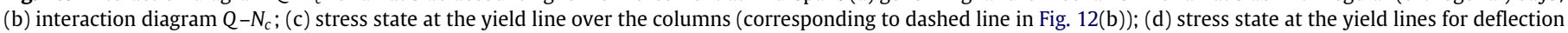
downwards at mid-span; and (e) stress state at the yield line for deflection upwards at mid-span.

With respect to the $Q-N_{c}$ interaction diagram of a flat slab (Fig. 13), it can be calculated on the basis of Eqs. (10)-(13) or (14)-(16) by adding the contribution of the reinforcement at midspan. To do so, the reinforcement ratios $\rho$ and $\rho^{\prime}$ of the previous equations refer to those of the yield line developed through the columns (yield lines "1" in Fig. 13). The contribution of the reinforcement crossing the yield line at mid-span (yield line type "2" in Fig. 13) can be evaluated through the following term:

$\Delta Q^{+,-}=2 \frac{m_{p l, 2}^{+,-} b_{s}}{b_{q}-c / 2}$

where the plastic moment of the yield line at mid-span is calculated using the bottom flexural reinforcement $\left(m_{p l, 2}^{+}\right)$if the displacements at this line are downwards (typical cases for design). In other cases, where this line deflects upwards, the value $m_{p l, 2}^{-}$(plastic moment calculated with the top reinforcement at mid-span) is to be used. Fig. 13(b) shows the influence of the contribution of the reinforcement at mid-span for both situations. The contribution of the yield line at mid-span is also shown in Fig. 13(c-e).

With respect to the maximum crushing strength of the joint, it is limited by the compressive stress that can be developed by the concrete of the slab confining the inner prism. Assuming no confinement out of the plane of the slab (no transverse reinforcement) the maximum compressive stress the slab can provide is equal to the uniaxial compressive strength $\left(f_{c}\right)$, leading to:

$Q+N_{c} \leq 5 f_{c} A_{c}$.

For applications to actual flat slabs, it is still necessary to define an equivalent slab width $\left(b_{s}\right)$ as well as an equivalent position of the loads of the slab $\left(b_{q}\right)$. For inner columns, the equivalent slab width can be taken equal to the span length $\left(b_{s}=l\right.$, a justification of this hypothesis on the basis of a compatibility-based model can be found elsewhere [19]) accounting for the length of the yield lines. For edge or border columns, no increase of the compressive strength can be accounted for unless slab overhangs are provided. In such cases, the span length $l$ has to be replaced by twice the overhang $l_{0}$ (see Fig. 13(a)).

With respect to the equivalent position of the loads $\left(b_{q}\right)$ it depends on the governing failure mechanism. For a flat slab with regular (orthogonal) bays, such a mechanism is shown in Fig. 13(a), leading to:

$b_{q}=\frac{\ell-2 c+c^{2} / \ell}{4} \approx \frac{\ell-2 c}{4}$.

A comparison of the simplified design approach discussed in this section to the tests presented in this paper is shown in Fig. 12b for specimens PG31 to PG 34 (specimens subjected exclusively to column loading). The strength is accurately estimated, with a very limited scatter of test results (coefficient of variation of $3 \%$, refer to Table 2). In Fig. 12(c) the interaction diagrams of specimens PG13 and PG35 calculated with the simplified design approach (dashed lines) are compared to the ones calculated with the refined method. This comparison yields also almost same results for both methods.

\section{Conclusions}

The present paper describes the main results of a test programme on 6 slab-column joints where the concrete between column plates was confined only by the top and the bottom flexural reinforcement. Four specimens were subjected exclusively to column loading and two were subjected to column and slab loading. All specimens developed a plastic mechanism at maximum load and exhibited significant deformation capacity. Testing, in addition to a model grounded on the theory of plasticity to interpret the results, show that:

1. Inner slab-column joints reinforced only with flexural reinforcement allow carrying column loads significantly larger than those corresponding to the uniaxial compressive strength of the concrete of the slab. 
2. The increase on the concrete strength between column plates is due to the development of confinement stresses. Such stresses are originated by the flexural reinforcement of the rest of the slab, which acts as a tension ring restraining the lateral expansion of the joint.

3. Under confinement stresses, concrete exhibits a very ductile response. As a consequence, plasticity-based approaches are suitable to estimate the strength of slab-column joints.

4. Due to this fact, strength reductions due to transverse strains of concrete can be neglected even after yielding of the bending reinforcement.

5. For practical applications, the maximum strength of a slab subjected to column loading can be calculated using a simplified (rigid-plastic) distribution of confinement stresses.

6. When loads are applied to the slab (in addition to column loads), the plastic mechanism developed at failure may be modified depending on the ratio of loads applied to the slab and to the columns. The strength in such cases can be calculated on the basis of a series of licit stress fields in the slab.

7. A comparison between test results and the proposed approach leads to very good correlation for all failure modes investigated.

\section{Acknowledgement}

The authors thank Damien Dreier (EPFL) for his help during the development of the confined concrete constitutive law presented in Appendix.

\section{Appendix}

This Appendix presents a model for evaluating the behaviour of concrete in compression under confined conditions. It extends a previous model of the authors [24] and provides the stress-strain response of concrete in the longitudinal and transversal directions.

Longitudinal stress $\left(\sigma_{3}\right)$ is calculated as a function of longitudinal strains $\left(\varepsilon_{3}\right)$ and confinement conditions as:

$\sigma_{3}=(\alpha-1) \frac{\varepsilon_{3} E_{c c}}{\alpha-1+\left(\frac{\varepsilon_{3}}{\varepsilon_{3, p}}\right)^{\alpha}}$

where $E_{c c}$ refers to the confined modulus of elasticity and $\varepsilon_{3, p}$ to the strain at peak load. Both values can be calculated on the basis of the following formulas:

$E_{c c}=\frac{E_{c}}{1-2 v_{c} \gamma}$

$\varepsilon_{3, p}=\frac{\alpha f_{c c}}{E_{c c}(\alpha-1)}$

where $\gamma$ is the ratio between the confinement (transverse) stress $\sigma_{\text {lat }}$ and the uniaxial concrete compressive strength $f_{c}$ :

$\gamma=\frac{\sigma_{\text {lat }}}{f_{c}}$

The strength of concrete under confined conditions $\left(f_{c c}\right)$ can be estimated as a function of confinement stresses. Good agreement to test results can for instance be obtained by using the expression proposed by Farhad and Li [25]:

$f_{c c}=f_{c}+\alpha_{f} f_{c}^{1-\beta_{f}} \sigma_{\text {lat }}^{\beta_{f}}$

where the authors of this paper propose to use $\alpha_{f}=3.0$ and $\beta_{f}=2 / 3$ (values calculated from 41 test results, see Fig. 5(b)). For confinement stresses below $0.6 f_{c}$ (case of slab-column joints, refer to Fig. 6(d)) it is however sufficiently accurate to use a linear approximation, see Fig. 5(b). For instance, the values obtained using the theory of plasticity assuming a Mohr-Coulomb yield criterion with an associative flow rule and a value of the friction angle of concrete equal to $\varphi=37^{\circ}$, are $\alpha_{f}=k=4.0$ and $\beta_{f}=1.0$ (similar values as those proposed by Richart [10]):

$f_{c c}=f_{c}+k \sigma_{\text {lat }}$.

With respect to coefficient $\alpha$, it refers to concrete brittleness, where the following values have a physical meaning:

$-\alpha=1.0$ leads to a plastic plateau for $\sigma_{3}=f_{c c}$;

$-\alpha>1.0$ leads to a compression softening after reaching its maximum strength. For larger values of $\alpha$, the surface below the stress-strain curve is reduced with a larger negative slope (more brittle behaviour).

Concrete brittleness is assessed on the basis of two factors: concrete uniaxial compressive strength (more ductile behaviour for lower concrete strength) and confinement (more ductile behaviour for larger confinement). The following formula is proposed for coefficient $\alpha$ :

$\alpha=\frac{\alpha_{c}+a \gamma}{\delta+\alpha_{c}(1-\delta)+a \gamma} \geq 1.0$

where $\delta$ is the ratio:

$\delta=\frac{f_{c c}}{E_{c c}} \frac{E_{c}}{f_{c}}$

and $\alpha_{c}$ refers to $\alpha$ for unconfined conditions:

$\alpha_{c}=1.5+\frac{f_{c}}{75}+\frac{f_{c}^{2}}{4500}$ where $f_{c}$ is in $(\mathrm{MPa})$.

Coefficient $a$ can be fitted on the basis of several tests under confined conditions. A value $a=40$ is proposed to be used on the basis of the test results of the literature [10-15].

With respect to transverse expansion of concrete, three different regimes are considered [26]:

- for moderate stresses, $\sigma_{3}$ lower than approximately $0.8 f_{c c}$, the elastic behaviour applies (value of the Poisson's coefficient $v=$ $v_{c}=0.2$;

- thereafter, longitudinal microcracking develops and the value of the Poisson's coefficient increases. At maximum strength $\sigma_{3}=f_{c c}$, a constant value of $v=0.5$ can be adopted with rather good agreement with test results;

- after reaching the maximum strength, and while concrete is in its softening phase, transverse strains (and thus coefficient $v$ ) continue to increase.

Such behaviour can be described on the basis of transverse strains $\left(\varepsilon_{1}\right)$ as a function of longitudinal strains $\left(\varepsilon_{3}\right)$ assuming the following law:

$\varepsilon_{1}= \begin{cases}v_{c} \varepsilon_{3}-\frac{\sigma_{1}}{E_{c c}}\left(1-v_{c}\right) & \text { if } \varepsilon_{3} \leq \varepsilon_{3, c} \\ a_{\varepsilon} \varepsilon_{3}^{2}+b_{\varepsilon} \varepsilon_{3}+c_{\varepsilon} & \text { if } \varepsilon_{3}>\varepsilon_{3, c}\end{cases}$

where: $\varepsilon_{3, c}=\varepsilon_{3}\left(\sigma_{3}=0.8 f_{c c}\right)$. This equations accounts for a linear (elastic) phase prior to development of microcracking followed by a more than proportional increase of transverse strains thereafter. Parameters $a_{\varepsilon}, b_{\varepsilon}$ and $c_{\varepsilon}$ can be determined imposing:

- equality of transverse strains at $\varepsilon_{3, c}$ between both regimes;

- equality of the slope of both regimes at $\varepsilon_{3}=\varepsilon_{3, c}$;

- lateral strain at maximum strength $\varepsilon_{3}=\varepsilon_{3, p}$ equal to $v=0.5$.

Thus, it results in:

$a_{\varepsilon}=\frac{\varepsilon_{1, p}-\varepsilon_{1, c}+v_{c}\left(\varepsilon_{3, c}-\varepsilon_{3, p}\right)}{\left(\varepsilon_{3, p}-\varepsilon_{3, c}\right)^{2}}$

$b_{\varepsilon}=v_{c}-2 a_{\varepsilon} \varepsilon_{3, c}$

$c_{\varepsilon}=\varepsilon_{1, c}-a_{\varepsilon} \varepsilon_{3, c}^{2}-b_{\varepsilon} \varepsilon_{3, c}$.

Fig. A.1 compares the results of the model to a series of test results, showing very good performance both in terms of predicting the strength (calculated with $\alpha_{f}=3.0$ et $\beta_{f}=2 / 3$ ) and transverse deformation before and after peak load. 

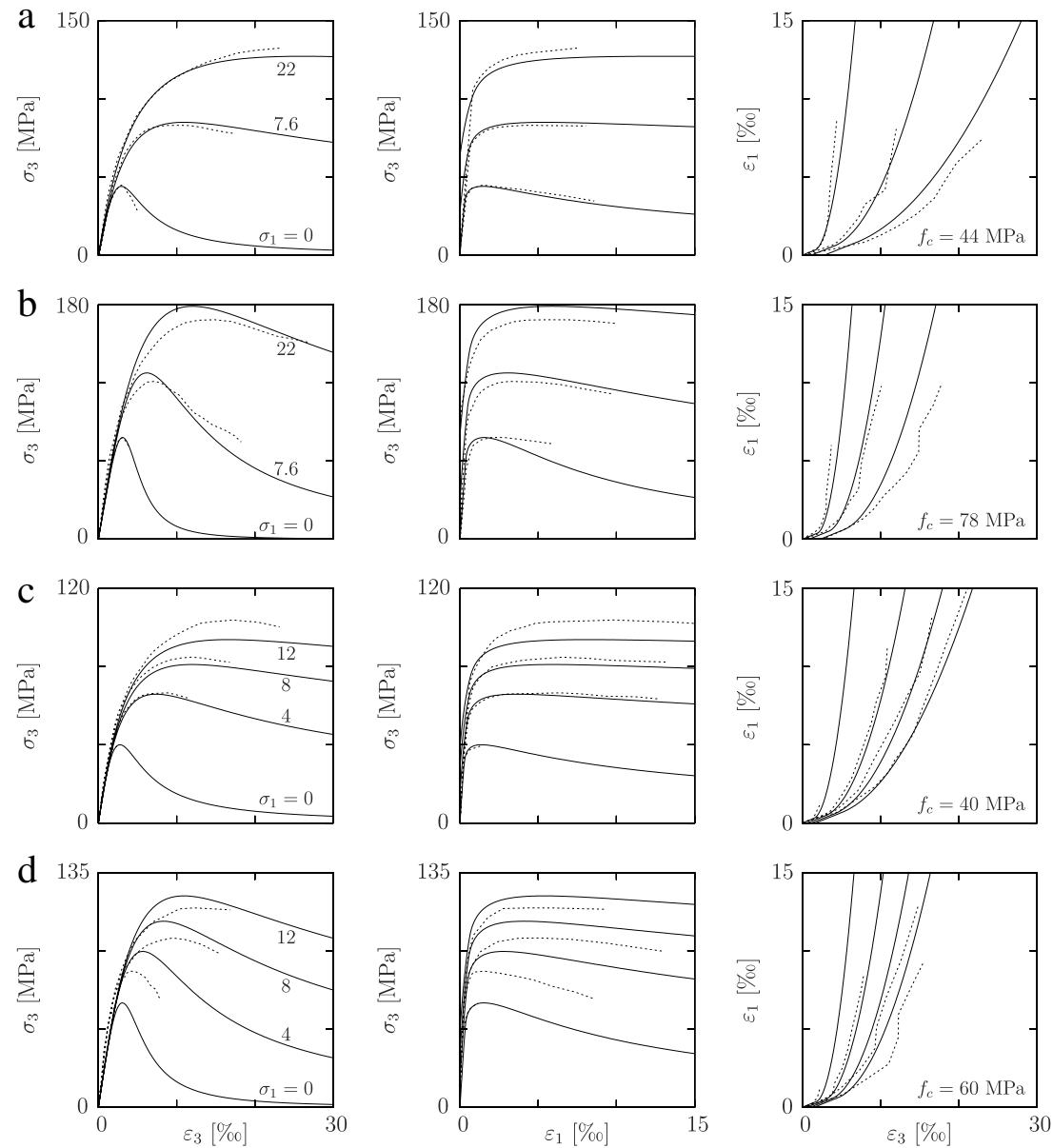

Fig. A.1. Comparison between experimental tests (dashed lines) and test predictions (continuous lines): (a) Lahlou 1992 [11] series OC $\left(f_{c}=44 \mathrm{MPa} ; \sigma_{1}=0 / 7.6 / 22 \mathrm{MPa}\right.$ ); (b) Lahlou 1992 [11] series HSC ( $f_{c}=78 P a ; \sigma_{1}=0 / 7.6 / 22 \mathrm{MPa}$ ); (c) Candappa 2001 [15] series U40 ( $\left.f_{c}=40 \mathrm{MPa} ; \sigma_{1}=0 / 4 / 8 / 12 \mathrm{MPa}\right)$ et; (d) Candappa 2001 [15] series $\mathrm{U} 60\left(f_{c}=60 \mathrm{MPa} ; \sigma_{1}=0 / 4 / 8 / 12 \mathrm{MPa}\right)$.

\section{References}

[1] Guidotti R. Investigation on the structural behaviour of reinforced concrete slab-column joints (Etude du comportement structural des joints colonnes-dalle dans les planchers dalle en béton armé). Master thesis report. École Polytechnique Fédérale de Lausanne; 2007. 64 pp [in French].

[2] Bianchini AC, Woods RE, Kesler CE. Effect of floor concrete strength on column strength. J Amer Concr Inst ACI 1960;1149-69.

[3] Gamble WL, Klinar JD. Tests of high-strength concrete columns with intervening floor slabs. J Struct Eng ASCE 1991;117(5):1462-76.

[4] Ospina CE, Alexander SDB. Transmission of interior concrete column loads through floors. J Struct Eng ASCE 1998;124(6):602-10.

[5] McHarg PJ, Cook WD, Mitchell D, Yoon Y-S. Improved transmission of highstrength concrete column loads through normal strength concrete slabs. ACI Struct J 2000;97:157-65.

[6] Shah AA, Dietz J, Tue VN. Experimental investigation of column-slab joints. ACI Struct J 2005;102(1):103-13.

[7] Guidotti R, Fernández Ruiz M, Muttoni A. Punching of flat slabs subjected to large column loads. Durchstanzen von Flachdecken bei hohen Stützenlasten. Beton- und stahlbetonbau, Vol. 105, No. 1. Berlin: Ernst \& Sohn, Wiley; 2010. p. 19-26 [in German].

[8] Guandalini S, Burdet O, Muttoni A. Punching tests of slabs with low reinforcement ratios. ACI Struct J 2009;106(1):87-95.

[9] Muttoni A. Punching shear strength of reinforced concrete slabs without transverse reinforcement. ACI Struct J 2008;105(4):440-50.

[10] Richart FE, Brandtzaeg A, Brown RL. A study of the failure of concrete under combined compressive stresses. Engineering Experiment Station, University of Illinois, Bulletin No. 185. 1928, 102 pp.

[11] Lahlou K, Aïtcin P-C, Chaallal O. Behaviour of high-strength concrete under confined stresses. Cement Concr Compos 1992;14:185-93.

[12] Imran I, Pantazopoulou SJ. Experimental study of plain concrete under triaxial stress. ACI Mater J 1996;93(6):589-601.

[13] Attard MM, Setunge S. Stress-strain relationship of confined and unconfined concrete. ACI Mater J 1996;93(5):1-11.
[14] Ansari F, Li Q. High-strength concrete subjected to triaxial compression. ACI Mater J 1998;95(6):747-55.

[15] Candappa DC, Sanjayan JG, Setunge S. Complete triaxial stress-strain curves of high-strength concrete. J Mater Civil Eng 2001;13(3):209-15.

[16] Muttoni A. The applicability of the theory of plasticity (Die Anwendbarkeit der Plastizitätstheorie in der Bemessung von Stahlbeton). Ph.D. thesis. Institut für Baustatik und Konstruktion ETH Zürich, Report 176. Birkhäuser Verlag, Basel, Switzerland, 1990, 158 pp [in German].

[17] Vecchio FJ, Collins MP. The modified compression field theory for reinforced concrete elements subjected to shear. Amer Concr Inst J 1986; 83(March-April):219-31.

[18] Belarbi A, Hsu C-TT. Constitutive laws of softened concrete in biaxial tensioncompression. ACI Struct J 1995;92(5):562-73.

[19] Guidotti R. Punching of flat slabs subjected to large column loads (Poinçonnement de planchers-dalles avec colonnes superposées fortement sollicitées). Ph.D. thesis. École Polytechnique Fédérale de Lausanne. 2010. 187 p [in French].

[20] Nielsen MP. Limit analysis and concrete plasticity. 2nd ed. CRC Press; 1999. p. 908.

[21] Cox AD, Eason G, Hopkins HG. Axially symmetric plastic deformations in soils. Philos Trans R Soc Lond Ser A Math Phys Sci 1961;254(1036):1-45.

[22] Hill JM, Wu H-W. Some axially symmetric flows of Mohr-Coulomb compressible granular materials. Proc Math Phys Sci 1992;438(1902):67-93.

[23] Exner H. Theory of plasticity for Coulomb materials (Plasticitetsteori for Coulomb Materialer). Ph.D. thesis. Technical University of Denmark, Serie R, No $175,1983,258$ pp [in Danish].

[24] Fernández Ruiz M, Muttoni A, Gambarova P. Relationship between nonlinear creep and cracking of concrete under uniaxial compression. J Adv Concr Technol 2007;5(3):383-93.

[25] Fahrad A, Li Q. High-strength concrete subjected to triaxial compression. ACI Mater J 1998;95(6):747-55.

[26] Redaelli D. Behaviour and modelling of Ultra-High Performance Fiber reinforced concrete structural members with ordinary reinforcement (Comportement et modélisation des éléments de structures en Béton Fibré à Ultra-Hautes Performances avec armatures passives). Ph.D. thesis. École Polytechnique Fédérale de Lausanne, No 4298, 2009, 285 p [in French]. 